\title{
Severe Neonatal Anaemia, MRI Findings and Neurodevelopmental Outcome
}

\author{
Inge A. Zonnenberg ${ }^{a}$ R. Jeroen Vermeulen ${ }^{b}$ Maartje W. Rohaan ${ }^{a}$ \\ Mirjam M. van Weissenbruch ${ }^{a}$ Floris Groenendaal ${ }^{c}$ Linda S. de Vries ${ }^{c}$ \\ Departments of a Neonatology and ${ }^{b}$ Child Neurology, Neuroscience Campus Amsterdam, VU University Medical \\ Center, Amsterdam, and 'Department of Neonatology, Wilhelmina Children's Hospital/University Medical Center \\ Utrecht, Utrecht, The Netherlands
}

\section{Key Words}

Severe neonatal anaemia $\cdot$ MRI findings .

Neurodevelopmental outcome

\begin{abstract}
Background and Objective: Severe neonatal anaemia can impair cerebral oxygen supply. Data on long-term outcomes following severe neonatal anaemia are scarce. Methods: Clinical data and neurodevelopmental outcome of 49 (near) term infants with haemoglobin concentration after birth $<6.0 \mathrm{mmol} / \mathrm{l}$ were retrospectively collected and analysed. In a subgroup of 28 patients, amplitude-integrated EEG was available and in 25 infants cerebral MRI was obtained. Infants were followed up at 14-35 months of age and assessed with the Griffiths Scale of Mental Development or Bayley Scale of Infant Development. Results: Eighteen patients (37\%) died during the neonatal period. In 25 patients MRI was performed. A predominant pattern of injury on MRI was seen in the basal ganglia and thalami in 7 patients (28\%), whereas some form of white matter injury was present in 16 (64\%) and a combination in $3(12 \%)$. Follow-up data were available for 26 patients (84\% of survivors). Formal assessment of neurodevelopmental outcome was performed in 20 of 31 (65\%) infants who survived (median age: 19 months, range: 14-35).
\end{abstract}

Sixteen infants (80\%) had a developmental quotient appropriate for age in the first 2 years after birth. On motor outcome, 1 patient (5\%) scored below average (Z-score -1.10). One patient developed cerebral palsy. Conclusion: Early neurodevelopmental outcome in surviving patients with severe neonatal anaemia was within the normal range in the majority of the survivors. MRI showed mild-to-moderate white matter injury in two thirds of the infants. Prospectively collected data with a longer follow-up period are needed.

C 2016 The Author(s) Published by S. Karger AG, Basel

\section{Introduction}

Neonatal anaemia has a diverse aetiology, and it can cause an acute life-threatening situation through hypovolaemic shock and hypoxia at birth, as well as through multiple organ failure in the first days of life. During hypovolaemic shock, redistribution of blood flow occurs and may be preferentially directed to the brain, which possibly prevents more severe adverse neurological sequelae. Anaemia may result in encephalopathy, which can be assessed using aEEG (amplitude-integrated EEG).

Data on MRI findings and neurodevelopmental outcome of survivors of neonatal anaemia are limited. Since

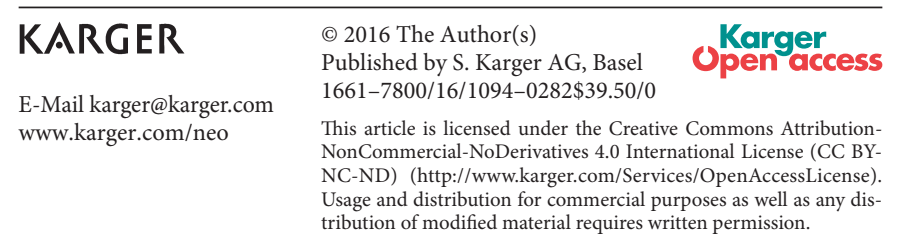

I.A. Zonnenberg

Department of Neonatology, VU University Medical Center De Boelelaan 1117

NL-1081 HV Amsterdam (The Netherlands)

E-Mail i.zonnenberg@vumc.nl tribution of modified material requires written permission. 
severe anaemia is often associated with perinatal asphyxia, it is hard to distinguish with neuro-imaging whether cerebral injury is due to anaemia or the associated hypoxia-ischaemia.

The aim of this retrospective study is to describe aEEG and MRI findings following severe neonatal anaemia in (near) term infants admitted at a level III neonatal intensive care unit, and relate these findings to neurodevelopmental outcome at approximately 2 years of age.

\section{Methods}

We retrospectively collected clinical data from medical records of patients who presented with severe anaemia in the neonatal intensive care unit of the VU Medical Center, Amsterdam, or the Wilhelmina Children's Hospital, University Medical Center, Utrecht, between January 2000 and June 2011.

Patients with an initial haemoglobin $(\mathrm{Hb})$ concentration $<6.0$ $\mathrm{mmol} / \mathrm{l}([\mathrm{mg} / \mathrm{dl}]=[\mathrm{mmol} / \mathrm{l}] \times 1.61)$ and a gestational age $\geq 36$ weeks were eligible for this study. Infants with chromosomal abnormalities or inborn errors of metabolism were excluded.

In 9 patients, the first $\mathrm{Hb}$ concentration was measured after a blood transfusion had already been administered immediately after birth. Initial $\mathrm{Hb}$ concentrations were therefore estimated, based on the fact that a blood transfusion of $20 \mathrm{ml} / \mathrm{kg}$ increases $\mathrm{Hb}$ concentration by approximately $3.0 \mathrm{mmol} / \mathrm{l}$. These estimated values were used as the initial $\mathrm{Hb}$ concentrations.

Various clinical data of vital organ failure were collected, including the need for respiratory or circulatory support and the aEEG background pattern.

MRI Analysis

MRI in the VU Medical Center was performed on a 1.5-tesla magnet (Siemens Vision, Erlangen, Germany). The MRI protocol included T1, T2 and diffusion-weighted images (DWI). In the Wilhelmina Children's Hospital, the same sequences were obtained on a 1.5-tesla MRI, and more recently on a 3-tesla MRI (ACS-NT System and Achieva, respectively; Philips Medical Systems, Best, the Netherlands).

We assessed predefined brain areas on both conventional imaging and DWI. The MRI score described by Rutherford was used (Appendix 1). The separate areas of interest were scored in three categories: (1) no abnormalities (no abnormalities on T1- and T2weighted images), (2) mild abnormalities (focal regions of abnormal signal intensity) and (3) moderate-to-severe abnormalities (multiple regions of abnormal signal intensity).

\section{Outcome}

Neurodevelopmental and neuromotor function follow-up were assessed with either the Griffiths Scale of Mental Development (GMDS), Bayley Scales of Infant Development, ed. 2, Dutch version (BSID-II-NL), or, more recently, Bayley Scales of Infant Development, ed. 3 (BSID-III). In order to enable the comparison of these different developmental tests, Z-scores were calculated for GMDS [performance developmental quotient used for neurodevelopment and the locomotor developmental quotient used for motor development], BSID-II-NL [mental developmental index

Severe Neonatal Anaemia, MRI Findings

and Neurodevelopmental Outcome

Table 1. Patient characteristics

Gestational age, weeks

Birth weight, $g$

Sex, male

Apgar score at $5 \mathrm{~min}$

$\mathrm{pH}$ (umbilical cord or first $\mathrm{pH}$ )

Lactate max.

$\mathrm{Hb}$ concentration, $\mathrm{mmol} / \mathrm{l}$

Survival

aEEG performed

aEEG background pattern

documented

MRI performed

Survivors with MRI imaging

Neurodevelopmental assessment of survivors $(\mathrm{n}=31)$

Neurodevelopmental assessment and MRI

Values are given as $\mathrm{n}(\%)$ or median (range).

and psychomotor developmental index], and BSID-III composite score outcomes. Z-scores were calculated as follows: [(score - test mean)/standard deviation (SD)] for each test. Development was classified as either mildly delayed (Z-score $\leq-1)$ or normal (Zscore $>-1)$. If neurodevelopmental tests were not performed, parents and/or general practitioners were contacted by phone to obtain the most recent status of neurodevelopment.

\section{Statistical Analysis}

Comparisons were made between groups with initial $\mathrm{Hb}$ concentrations $\leq 3.0 \mathrm{mmol} / \mathrm{l}$ and $3.1-6.0 \mathrm{mmol} / \mathrm{l}$, as well as between surviving and deceased patients. Comparisons were also made between groups with and without MRI abnormalities. We used a $\chi^{2}$ test and the Mann-Whitney $U$ test for categorical and continuous variables, respectively. $\mathrm{p}<0.05$ was considered statistically significant. Statistical analyses were performed using SPSS Software Package version 20.

\section{Results}

Patient characteristics are presented in table $1 . \mathrm{Hb}$ concentrations were measured at birth or within several hours after birth and ranged from 1.0 to $5.9 \mathrm{mmol} / \mathrm{l}$.

\section{Aetiology of Neonatal Anaemia}

The most frequent causes of anaemia were foetomaternal haemorrhage (30.6\%) and exsanguination (26.5\%) due to vasa or placenta praevia. Less common causes were twin-to-twin transfusion syndrome (8.2\%), placental abruption $(8.2 \%)$, bleeding due to a traumatic delivery 
Table 2. Clinical characteristics of survivors versus deceased, and $\mathrm{Hb}$ concentration below or above $3.0 \mathrm{mmol} / \mathrm{l}$

\begin{tabular}{|c|c|c|c|c|c|c|}
\hline & $\begin{array}{l}\text { Survivors } \\
(\mathrm{n}=31)\end{array}$ & $\begin{array}{l}\text { Deceased } \\
(\mathrm{n}=18)\end{array}$ & $\mathrm{p}$ & $\begin{array}{l}\mathrm{Hb}<3.0 \\
\mathrm{mmol} / 1 \\
(\mathrm{n}=14)\end{array}$ & $\begin{array}{l}\mathrm{Hb} 3.1-6.0 \\
\mathrm{mmol} / 1 \\
(\mathrm{n}=35)\end{array}$ & $\mathrm{p}$ \\
\hline Invasive resp. support & $24(77)$ & $18(100)$ & 0.030 & $14(100)$ & $28(80)$ & 0.073 \\
\hline Vasopressors & $19(61)$ & $18(100)$ & 0.002 & $11(79)$ & $26(74)$ & 0.759 \\
\hline Glucose $<2.0 \mathrm{mmol} / 1$ & $9(29)$ & $6(33)$ & 0.759 & $6(43)$ & $9(26)$ & 0.309 \\
\hline aEEG pattern BS/FT & $4 / 19(21)$ & $7 / 9(89)$ & 0.003 & $1 / 6(17)$ & $10 / 22(45)$ & 0.215 \\
\hline MRI performed & $20(65)$ & $5(28)$ & 0.013 & $6(43)$ & $19(54)$ & 0.480 \\
\hline $\mathrm{Hb}<3.0 \mathrm{mmol}$ & $9(29)$ & $5(28)$ & 0.927 & & & \\
\hline Survival & & & & $9(64)$ & $22(63)$ & 0.927 \\
\hline
\end{tabular}

Values are given as $\mathrm{n}(\%) . \mathrm{BS}=$ Burst suppression; $\mathrm{FT}=$ flat trace, $\chi^{2}$ test. Statistically significant differences are in italics.

(8.2\%), umbilical cord rupture (6.1\%), haemolysis (6.1\%) and complications during caesarean section (2.0\%). In $4.1 \%$, the aetiology remained unknown. As hydrops was not present in any patient, the onset of the severe anaemia was most likely to be (sub)acute. Reticulocyte count data would have been useful to help determine the time of onset of the anaemia, but these data were not available in most of the infants.

\section{Clinical Characteristics}

Invasive mechanical ventilation was required in $85.7 \%$, and non-invasive respiratory support (continuous positive airway pressure) in $14.3 \%$. Circulatory support with vasopressors was needed in $75.5 \%$ of the patients. There were no significant differences in the need for vital organ support or mortality between the two $\mathrm{Hb}$ concentration groups (table 2).

Thirteen patients (31\%) had at least one glucose concentration $<2.0 \mathrm{mmol} / \mathrm{l}$. There were no differences in mortality (Fisher's exact test, $\mathrm{p}=0.759$ ), morbidity [Fisher's exact test, need for respiratory support $p=0.186$, need for circulatory support $\mathrm{p}=0.636$, and convulsions (either clinical or electrographic) $\mathrm{p}=0.612$ ] or neurodevelopment or motor development $\left(\chi^{2}, \mathrm{p}=0.954\right.$ and $\mathrm{p}=$ 0.683 , respectively) between normoglycaemic and hypoglycaemic patients.

\section{aEEG Characteristics}

Clinical or subclinical seizures were noted in $61.2 \%$ of the infants $(n=30)$. Of these, $43.3 \%$ of the infants $(n=13)$ needed one, and $56.6 \%(\mathrm{n}=17)$ needed multiple anti-epileptic drugs. Most patients were monitored with aEEG during the first days after birth $(\mathrm{n}=42,86 \%)$. In 28 pa- tients, aEEG was available for assessment of the background pattern. The patterns recorded and scored during the first $12 \mathrm{~h}$ after birth were used. Continuous normal voltage was found in $50 \%(\mathrm{n}=14)$, discontinuous normal voltage in $7.1 \%(\mathrm{n}=2)$, burst suppression in $32.1 \%(\mathrm{n}=9)$, continuous low voltage in $3.6 \%(\mathrm{n}=1)$ and flat trace in $7.1 \%(n=2)$ of the infants. No differences in seizure activity (Fisher's exact test, $\mathrm{p}=0.754$ ) or aEEG background pattern (Fisher's exact test, $\mathrm{p}=0.355$ ) were observed for the two $\mathrm{Hb}$ concentration groups. The aEEG background patterns in the deceased group were more often non-favourable (burst suppression or flat trace; Fisher's exact test, $\mathrm{p}=$ 0.010). These non-favourable patterns were associated with motor developmental delay in the surviving patients $\left(\chi^{2}\right.$ test, $\left.p=0.001\right)$. For neurodevelopment, non-favourable patterns showed a trend towards delay $\left(\chi^{2}\right.$ test, $\left.p=0.100\right)$.

\section{Neonatal Outcome}

Eighteen patients (36.7\%) did not survive the neonatal period. Thirteen patients died within $72 \mathrm{~h}$ after birth, mainly due to acute multiple organ failure. The other 5 patients died following a decision to redirect care due to the expected serious long-term sequelae, based on clinical parameters (e.g. therapy-resistant convulsions) and/or extensive cerebral damage documented by MRI. The deceased patients had a significantly higher need for respiratory and circulatory support compared to the living patients, but there was no difference in the presence of seizure activity.

\section{MRI Analysis}

Imaging was performed in 25 patients between day 2 and day 8 after birth (median: day 6). Five of the patients 
Table 3. MRI findings in the total population

\begin{tabular}{llll}
\hline & $\begin{array}{l}\text { Conventional images } \\
(\mathrm{n}=25)\end{array}$ & $\begin{array}{l}\text { Diffusion- } \\
\text { weighted ima- } \\
\text { ges }(\mathrm{n}=19)\end{array}$ \\
\cline { 2 - 3 } & $\begin{array}{l}\text { severe } \\
\text { abnormalities }\end{array}$ & $\begin{array}{l}\text { mild } \\
\text { abnormalities }\end{array}$ & \\
\hline Occipital WM & $8(32)$ & $4(16)$ & $5(26)$ \\
Frontal WM & $6(24)$ & $6(24)$ & $4(21)$ \\
Temporal WM & $7(28)$ & $1(4)$ & $3(16)$ \\
All WM & $7(28)$ & $2(8)$ & $6(32)$ \\
WM injury $>1$ site & $5(20)$ & $3(12)$ & $3(21)$ \\
Basal ganglia and thalami \\
Internal capsule
\end{tabular}

Values are given as $\mathrm{n}(\%)$. WM $=$ White matter.

died, and MRI imaging was performed post-mortem in 3 of the patients. DWI images were available for 18 infants imaged during life. The clinical characteristics of infants with an MRI were not significantly different compared to the total study population.

In 3 deceased patients, MRI imaging was obtained post-mortem. In 1 deceased patient, DWI (MRI obtained during life on day 6) showed few abnormalities in contrast to the conventional images that were clearly abnormal, possibly due to antenatal onset of the anaemia.

\section{White Matter Injury}

In 16 of the 25 patients (64\%), some form of white matter injury was found, both in surviving and deceased patients. Severe widespread abnormalities were seen in 8 infants (32\%), 3 of whom died. Another 8 infants (32\%) had mild white matter lesions.

Severe lesions were seen in the occipital white matter $(\mathrm{n}=8)$ and slightly less often in the frontal $(\mathrm{n}=6)$ and temporal white matter $(n=7)$. Mild lesions were seen in occipital $(\mathrm{n}=4)$, frontal $(\mathrm{n}=6)$ and temporal white matter $(\mathrm{n}=1)$. White matter lesions were often present at more than one site (table 3 ).

No relation was found between white matter abnormalities and an unfavourable aEEG background pattern or the presence of hypoglycaemia $(n=28$, Fisher's exact test, $\mathrm{p}=0.315$ and $\mathrm{p}=0.205$, respectively). There were also no differences in locomotor developmental quotient/ psychomotor developmental index, performance developmental quotient/mental developmental index, or combined outcome death or motor/neurodevelopmental outcome (Z-score $<-1 ; \mathrm{n}=14, \chi^{2}$ test, $\mathrm{p}=0.901, \mathrm{p}=0.902$ and $\mathrm{p}=0.154$, respectively).

Severe Neonatal Anaemia, MRI Findings and Neurodevelopmental Outcome
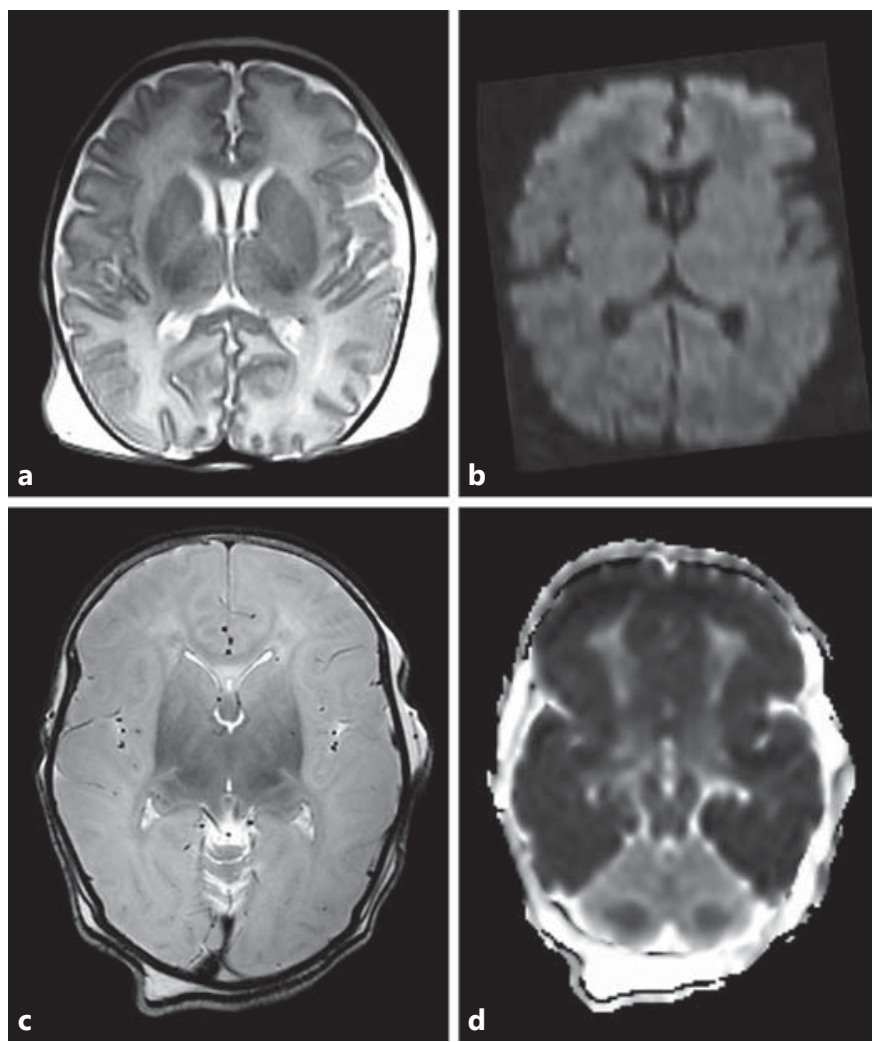

Fig. 1. MRI imaging. a, b MRI day 7: term born male with Apgar scores 5 and 6 at 1 and 5 min and an initial $\mathrm{Hb}$ concentration of $1.9 \mathrm{mmol} / 1$ [axial T2-weighted image at the level of the basal nuclei (a); axial DWI (b)]. Mild abnormalities in occipital white matter, not seen as increased signal intensity on DWI. The patient did not come to the follow-up appointments, but had a favourable outcome according to the general practitioner at the age of 2 years. c, d MRI day 2: term born female, Apgar scores 4 and 8 at 1 and 5 $\mathrm{min}$, and an initial $\mathrm{Hb}$ concentration of $5.6 \mathrm{mmol} / \mathrm{l}$ [axial T2weighted image (c); axial ADC map (d)]. Diffuse severe abnormalities throughout the cortex and white matter; near-total brain injury (ADC thalami $700 \times 10^{-6} \mathrm{~mm}^{2} / \mathrm{s}$, basal ganglia $850 \times 10^{-6}$ $\mathrm{mm}^{2} / \mathrm{s}$ ). Care was redirected.

\section{Basal Ganglia/Thalamic Injury}

Abnormalities in the basal ganglia and thalami were seen in 7 infants. Moderate-to-severe abnormalities were only seen in 5 deceased infants, all of whom had associated white matter lesions. Mild basal ganglia/thalamic abnormalities were found in 2 (8\%) surviving patients, without associated white matter lesions.

\section{Comparison of Infants with $\mathrm{Hb}<3 \mathrm{mmol} / \mathrm{l}$ and}

3.1-5.9 $\mathrm{mmol} / \mathrm{l}$

Severity of anaemia did not show a relation with subsequent brain abnormalities. This is illustrated in fig- 
Table 4. Abnormal MRI findings (conventional images) of survivors versus deceased, and Hb concentration below or above $3.0 \mathrm{mmol} / \mathrm{l}$

\begin{tabular}{lllllll}
\hline & $\begin{array}{l}\text { Survivors } \\
(\mathrm{n}=20)\end{array}$ & $\begin{array}{l}\text { Deceased } \\
(\mathrm{n}=5)\end{array}$ & $\mathrm{p}$ & $\begin{array}{l}\mathrm{Hb}<3.0 \\
\mathrm{mmol} / \mathrm{l} \\
(\mathrm{n}=6)\end{array}$ & $\begin{array}{l}\mathrm{Hb} 3.1-6.0 \\
\mathrm{mmol} / \mathrm{l} \\
(\mathrm{n}=19)\end{array}$ & $\mathrm{p}$ \\
\hline Occipital WM & $7(35)$ & $5(100)$ & 0.035 & $5(83)$ & $5(26)$ & 0.121 \\
Temporal WM & $4(20)$ & $4(80)$ & 0.012 & $3(50)$ & $5(26)$ & 0.514 \\
Frontal WM & $7(35)$ & $5(100)$ & 0.060 & $3(50)$ & $9(47)$ & 0.926 \\
BGT & $3(15)$ & $5(100)$ & 0.001 & $1(17)$ & $7(37)$ & 0.624 \\
Internal capsule & $2(10)$ & $5(100)$ & $<0.001$ & $1(17)$ & $6(32)$ & 0.642 \\
Cerebellum & $1(5)$ & $5(100)$ & $<0.001$ & $1(17)$ & $5(26)$ & 0.733 \\
\hline
\end{tabular}

Values are given as $\mathrm{n}(\%) . \mathrm{WM}=$ White matter; BGT $=$ basal ganglia and thalami. Fisher's exact test.

ure 1. There was no difference in mortality between the two $\mathrm{Hb}$ concentration groups.

Cerebellar damage was seen in 6 infants, in both $\mathrm{Hb}$ concentration groups (table 4). Haemorrhagic lesions were found in 3 infants, while ischaemic lesions were found in the other 3 infants.

\section{Neurodevelopmental Outcome}

Neurodevelopmental test results were available in 20 of the 31 surviving patients (median age: 19 months, range: 14-35). The mean Z-score for neurodevelopment was 0.43 (SD 0.71). Only 1 patient (5\%) was mildly delayed (Z-score: -1.08 ). The mean Z-score for motor outcome was 0.58 (SD 0.81). One patient (5\%) was mildly delayed (Z-score: -1.10$)$. Unilateral spastic cerebral palsy was diagnosed in 1 patient with haemorrhagic cortical infarction. Of the 11 patients who were not formally tested, information was retrieved from the paediatrician, general practitioner or the parents. Cerebral palsy was not diagnosed in any of these patients, but behavioural problems were reported in 1 patient. Information about outcome could not be retrieved in 2 patients.

Thirteen of the 20 survivors with available MRI data were tested. The median age of testing was 24 months (range: 15-35). The mean Z-score for neurodevelopment was 0.37 (SD 0.76) and the mean Z-score for motor outcome was 0.67 (SD 0.88). No differences were found in neurodevelopmental and motor outcome between patients with no/mild white matter abnormalities and patients with moderate-to-severe white matter abnormalities.

There were no differences between the two $\mathrm{Hb}$ concentration groups for the neurodevelopmental outcome [mean Z-score: 0.33 (SD 0.79) and 0.73 (SD 0.59), respectively] and the motor outcome [mean Z-score: 0.62 (SD 0.88 ) and 0.49 (SD 0.62), respectively].

\section{Discussion}

In this retrospective study we were able to show that lesions in the basal ganglia and thalami, and especially in the white matter, are common findings in infants with severe neonatal anaemia.

Cerebral damage has been suggested to be caused by several pathophysiological mechanisms. In full-term infants, the deep grey matter nuclei are probably affected after an acute hypoxic-ischaemic insult due to changes in brain maturation and increased metabolic demands [1]. White matter injury is also found in full-term infants and is considered to be due to more prolonged and repetitive hypoxic-ischaemic events. A combination of deep grey matter damage and white matter lesions can also be found [2]. We hypothesize that the mechanisms that cause basal ganglia and white matter injury following severe anaemia might be similar to the mechanisms responsible for cerebral injury in full-term infants with perinatal asphyxia due to other causes. White matter injury has been described in animals as well as in humans after moderate prolonged foetal or neonatal asphyxia, as well as after neonatal hypoglycaemia $[3,4]$. It is important to note that a substantial percentage (31\%) of our anaemic patients also had a period of hypoglycaemia. The mechanism of injury due to hypoglycaemia is still unclear, although it has been hypothesized that it is caused by increased regional cerebral blood flow during hypoglycaemia with a subsequent reduction in regional glucose uptake [3]. 
Even more interesting are the clinical implications of these findings. MRI is a well-established method to assess brain injury in infants suffering from perinatal asphyxia, and these findings are closely related to later neurodevelopmental outcome [5-11]. Data on the longterm outcome of patients with severe acute anaemia combined with a less severe component of perinatal asphyxia are still limited. It is of interest that early neurodevelopmental and motor outcomes in the first 2 years of life in the survivors is favourable. In the absence of damage in the thalamus and basal ganglia, neonatal anaemia itself does not have a significant effect on outcome at 2 years of age [12]. However, the children are still young and their outcome should be re-assessed at school age. We also found that the severity of anaemia does not influence the need for intensive care treatment in the neonatal period. Moreover, we also found that there was no significant difference in survival between patients with an initial $\mathrm{Hb}$ concentration $\leq 3.0 \mathrm{mmol} / \mathrm{l}$ versus patients with an initial $\mathrm{Hb}$ concentration between 3.1 and $6.0 \mathrm{mmol} / \mathrm{l}$. There was also no increased need for respiratory or circulatory support in the infants with more severe anaemia. However, the degree of organ failure and especially the degree of encephalopathy scored clinically or with aEEG and the presence of seizure activity and severe injury on MRI were correlated with mortality and/or redirection of care.

\section{Limitations}

This retrospective study has several limitations. First, $\mathrm{Hb}$ concentrations were not assessed within a predefined time after birth. However, all $\mathrm{Hb}$ measurements were performed within $6 \mathrm{~h}$ after birth, indicating severe neonatal anaemia. Second, MRI imaging was initially restricted to infants with a clinical indication, although MRI was also performed in patients with anaemia without serious comorbidity. Although this may have caused a potential bias, clinical characteristics in infants with and without MRI data were not different. Third, a full neurodevelopmental assessment was not performed routinely. It would therefore be desirable to have a follow-up in these patients at school age to study whether the white matter lesions are associated with school performance, as has previously been shown in survivors with white matter injury in the context of hypoxic ischaemic encephalopathy [13]. More insight in the association between patterns of damage and possible pathophysiological mechanisms, combined with neurological outcome, will hopefully provide more insight in how to predict future disabilities during the newborn period.

Severe Neonatal Anaemia, MRI Findings

and Neurodevelopmental Outcome

\section{Conclusion}

Severe neonatal anaemia is associated with high neonatal mortality and neonatal morbidity. Those who survive perform relatively well when assessed at approximately 2 years of age.

MRI shows abnormalities in the basal ganglia and thalami in severely affected infants, and white matter lesions in most patients. However, it is difficult to distinguish between damage due to anaemia only and damage due to associated perinatal asphyxia.

Due to the retrospective setup of this study and missing data, results should be interpreted with caution. Prospectively collected data with a longer follow-up period are needed.

\section{Appendix 1: MRI Scoring System [10]}

Posterior limb of internal capsule: $0=$ normal, $1=$ reduced or asymmetrical signal intensity, and $2=$ severe injury with reversed or abnormal signal intensity bilaterally on T1- and or T2-weighted images.

Basal ganglia and thalami: $0=$ normal, $1=$ mild injury (focal abnormal signal intensity), 2 = moderate injury (multifocal abnormal signal intensity), and 3 = indicates severe injury (widespread abnormal signal intensity).

White matter: $0=$ normal, $1=$ mild injury (long T1 and T2 in periventricular white matter only), $2=$ long T1 and T2 in subcortical WM and or focal punctate lesions or focal infarction, and $3=$ severe widespread abnormalities including long $\mathrm{T} 1$ and $\mathrm{T} 2$, infarction, and haemorrhage.

Cortex: $0=$ normal, $1=$ mild $(1-2$ sites cortical highlighting/ decreased T1), $2=$ moderate $(3$ sites involved $)$ and $3=$ severe $(>3$ sites).

References

1 Wyatt JS: Mechanisms of brain injury in the newborn. Eye (Lond) 2007;21:1261-1263.

$\checkmark 2$ Okereafor A, Allsop J, Counsell SJ, Fitzpatrick J, Azzopardi D, Rutherford MA, Cowan FM: Patterns of brain injury in neonates exposed to perinatal sentinel events. Pediatrics 2008; 121:906-914.

-3 Burns CM, Rutherford MA, Boardman JP Cowan FM: Patterns of cerebral injury and neurodevelopmental outcomes after symptomatic neonatal hypoglycemia. Pediatrics 2008; $122: 65-74$.

4 Martinez-Biarge M, Bregant T, Wusthoff CJ, Chew AT, Diez-Sebastian J, Rutherford MA, Cowan FM: White matter and cortical injury in hypoxic-ischemic encephalopathy: antecedent factors and 2-year outcome. J Pediatr 2012;161:799-807. 
5 Alderliesten T, de Vries LS, Benders MJ, Koopman C, Groenendaal F: MR imaging and outcome of term neonates with perinatal asphyxia: value of diffusion-weighted MR imaging and (1)H MR spectroscopy. Radiology 2011;261:235-242.

6 Lally PJ, Price DL, Pauliah SS, Bainbridge A, Kurien J, Sivasamy N, Cowan FM, Balraj G, Ayer M, Satheesan K, Ceebi S, Wade A, Swamy R, Padinjattel S, Hutchon B, Vijayakumar M, Nair M, Padinharath K, Zhang H, Cady EB, Shankaran S, Thayyil S: Neonatal encephalopathic cerebral injury in South India assessed by perinatal magnetic resonance biomarkers and early childhood neurodevelopmental outcome. PLoS One 2014;9:e87874.

7 Martinez-Biarge M, Diez-Sebastian J, Kapellou O, Gindner D, Allsop JM, Rutherford MA, Cowan FM: Predicting motor outcome and death in term hypoxic-ischemic encephalopathy. Neurology 2011;76:2055-2061.
8 Martinez-Biarge M, Bregant T, Wusthoff CJ, Chew AT, Diez-Sebastian J, Rutherford MA, Cowan FM: White matter and cortical injury in hypoxic-ischemic encephalopathy: antecedent factors and 2-year outcome. J Pediatr 2012;161:799-807.

-9 Miller SP, Ferriero DM, Leonard C, Piecuch R, Glidden DV, Partridge JC, Perez M, Mukherjee P, Vigneron DB, Barkovich AJ: Early brain injury in premature newborns detected with magnetic resonance imaging is associated with adverse early neurodevelopmental outcome. J Pediatr 2005;147:609-616.

10 Rutherford M, Ramenghi LA, Edwards AD, Brocklehurst $\mathrm{P}$, Halliday $\mathrm{H}$, Levene $\mathrm{M}$, Strohm B, Thoresen M, Whitelaw A, Azzopardi D: Assessment of brain tissue injury after moderate hypothermia in neonates with hypoxic-ischaemic encephalopathy: a nested substudy of a randomised controlled trial. Lancet Neurol 2010;9:39-45.
1 Vermeulen RJ, van Schie PE, Hendrikx L, Barkhof F, van WM, Knol DL, Pouwels PJ: Diffusion-weighted and conventional MR imaging in neonatal hypoxic ischemia: twoyear follow-up study. Radiology 2008;249: 631-639.

2 Harteman JC, Groenendaal F, Toet MC, Benders MJ, Van Haastert IC, Nievelstein RA, Koopman-Esseboom C, de Vries LS: Diffusion-weighted imaging changes in cerebral watershed distribution following neonatal encephalopathy are not invariably associated with an adverse outcome. Dev Med Child Neurol 2013;55:642-653.

13 Perez A, Ritter S, Brotschi B, Werner H, Caflisch J, Martin E, Latal B: Long-term neurodevelopmental outcome with hypoxicischemic encephalopathy. J Pediatr 2013; 163 : 454-459. 